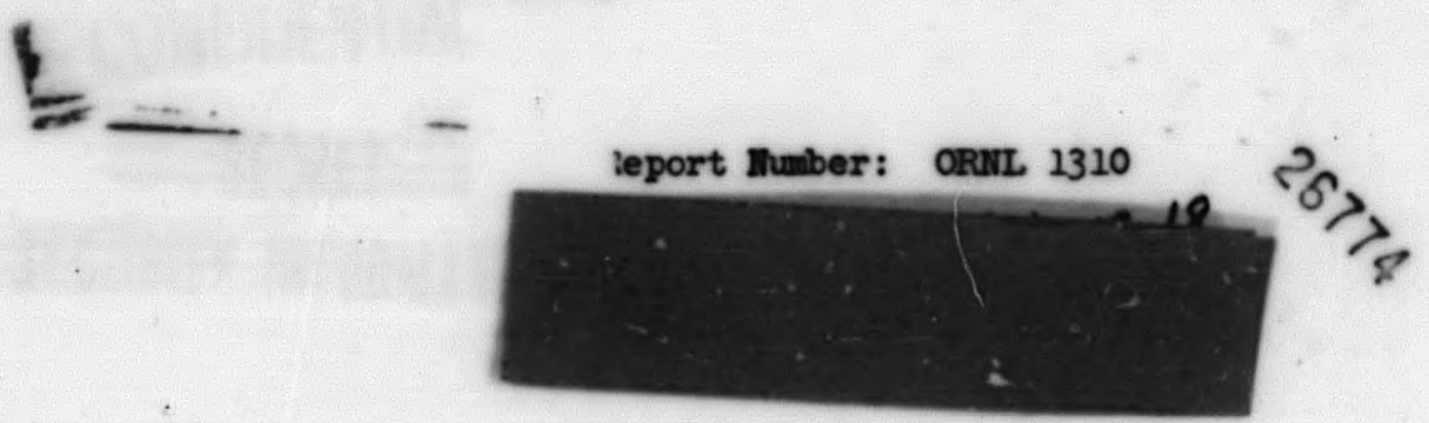

Contract No. W-7405, eng 26 ,

CHEMTCAL TECHNOLOGY DIVISIOIT

Laboratory Section

A COUNWERCURREIT SOLTD-LIOUID COMPACTOR

FOR COMPINOUS ION EXCHA EE

I. R. Higgins

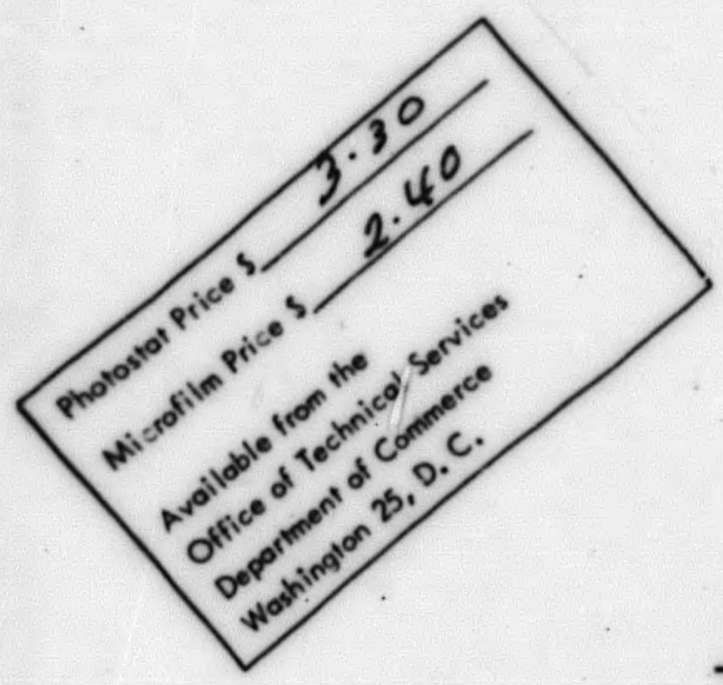

ISsuras

Esp 191952

OAK RIDGB MATIOHAL LABORATORY

Operated by

CARBIDE AND CARBOII CSERICAIS COMPANY

A Division of thion Carbide and Carbon Corporation

Post Office Bcox P

Oak R1dge, Tennessee 


\section{Table of Contents}

Pege No.

1.0 Abstract

2.0 Introduction

3.0 Summary 6

4.0 Mcknowledgrent 6

5.0 Equipment - veration 6

5.1 Devel the System 6

5.2 Deto _. Ament Operation 7

5.3 Development of the Bquipment 8

6.0 Bxamples of Recovery and Concentration 9

7.0 Examples of Separation 9

8.0 B1bliography 10

F1gures

5.1 Schematic diagram of the continuous countereurrent solid-11quid contactor

5.2 Original laboratory-scale hand-operated contactor

5.3 Laboratory-scale automatic contactor, showing column arrangement and motor-driven resin plug-valves.

5.4 Laboratory-scale autcanatic contactor showing cyele timer, alr-driven bellows, and air-driven solution plug-valves.

6.1 Recovery and concentration of ferrie 1ron on the cont 1nuous ion-exchange contactor.

6.2 Recovery and concentration of cerium on the continuous contactor. 


$$
-4-
$$

ORALL-1310

\section{Figures (eontinued)}

\section{Page No.}

7.1 Separation of cesium and uranium with the continuous

7.2 Separation of barium and strontium with the continuous 18 contactor. 


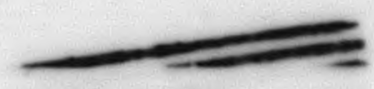

\subsection{ABSFRACT}

A continuous countercurrent solid-11quid contactor has been developed which retains the desirable features of the conventional $P$ ixed bed and gains the advantages of countereirrent flow. It can be adapted to many solid11 quid mass-transfer processes such a 1 on exehange, silles gel adsorption, and ore leaching.

\subsection{IIFRODUCIIOH}

In the last ten years theie has been a very rapid development in 1onexchange technology. The 1on-exchange method of chemical processing $1 \mathrm{~s}$ very attractive because of the high degree of separation possible in aimple and compact pieces of equipment. However, practically all applications enploy batchwise sorption-desorption vith fixed resin beds were neither the exchanger material nor the reagents are used with highest erficiency. For more extensive and econcanical application of 1on-exchange processes to AEC problems, development of a continuous countercurrent flow system seemed necessary. The advantages of continuous over fixed-bed lon exchange should be ifiliar to those found for continuous operation in other mass-tranafer systems, such as distillation and solvent extraction. More efficient utilization of resin and chemicals, lower fixed and operating costs, higher degree of separation and concentration, and improved unifornity of products are to be expected.

Several continuous 1on-exchange system have been propoged and developed. Most of the systems 1nvolve "dense" falling bed.(1-3, 6) Probably the greatest alsadvantage of the dense falling bed is the 11mitation placed on flow rates and solution densities to prevent fluidization or slooding. A device uslag 1 on-exchange membranes and electric current to separate 1ons continuously has been proposed $(1,4)$ which achieves many of the advantages to be expected from a continuous lon-exchange process.

The continuous system described in this report retains the rixed-bed advantages of placing almost no 11mitations on flow rates, solution deneities, and resin grading and at the same time gains the advantages of countereurrent Plow. 

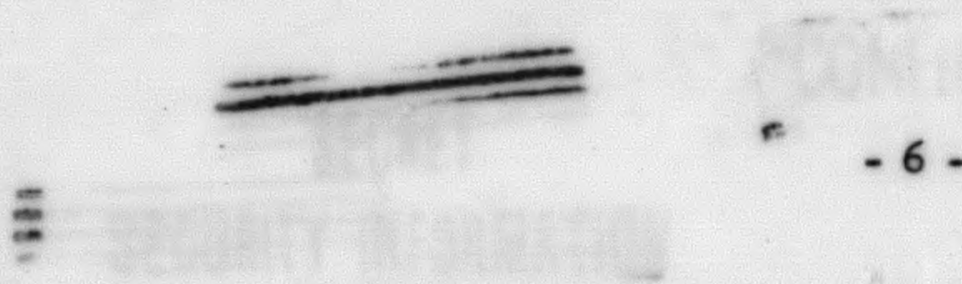

a.

$-6$.

ORIL-1310

\subsection{SUMenRY}

A continuous countereurrent contactor for 1on exchange, or other solid11quid mass-transfer processes, has been devised which retains the advantages of the conventional fixed bed and gains the advantages of countercurrent flow. Since the flow is against a packed bed, there is no limiting flow rate, and close control of flow rete is not required. The resin is moved by intermittently stopping the flow of solution and pulling or pushing the resin around in a piston-11ke manner, with no movement of particles relative to one another. The sorption and desorption sections are so arranged that loeded resin is pulled fram the feed end of the sorption column into the solution exit end of the desorption column. Regenerated resin fram the feed end of the desorption column is pulled into the solution exit end of the eorption column.

The continuity and superior efficiency of the operation compared to the conventional fixed bed has been demonstrated. (5) A fully autcmatic laboratory model has run continuously under steady-state conditions for over 100 hours. Bquipment development is continuing to simplify mechanical accessorles and to demonstrate the operation of larger scale equipment.

Anticipated application of this device include present ion-exchange processes in which continuous operation is desired and processes previously considered not feasible because of contacting inefficiency. For example, this contactor is simpler than equipment which approx imates continuous countereurrent flow by use of multiple columns in series and parallel; also in rediochemical processing the low hold-up times made possible might well eliminate the radiation damage problem.

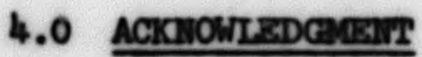

Recognition is given to A. C. Jealous for suggesting the use of a bellows for metered resin flow. T. A. Arehart and J. R. Parrott procured the equipment and constructed the laboratory automatic contactor. W. B. Shockley operated most of the demonstration rums and aided on equipment set-ups. T. M. Gayle of the Instrument Department designed and built timers and motorized valves. J. T. Roberts planned the "contest" experfments between the continuous contactor and the conventional fixed bed(5) and developed methods of analyzing the contactor operation.

\subsection{EQUIFVIIIT AND OPERATION}

\subsection{Develorment of the System}

The conventional Pixed 1on-exchange bed has several attractive features which should be retained, if possible, in the develogment of a continuous countereurrent contactor. High throughputs and solution densities are possible, and there is no particular need for elosely graded resin. The height

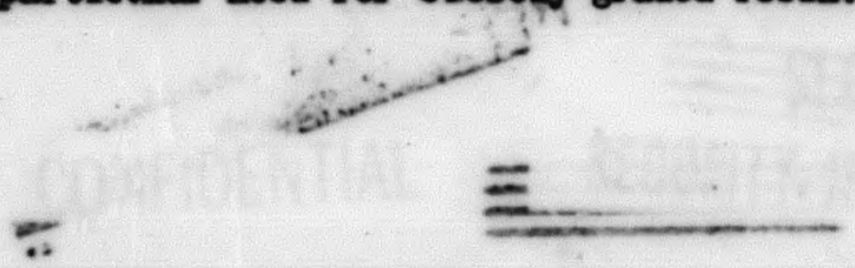




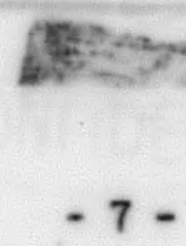

ORNL-1310

of a mass-transfer unit is at a minimum because the particles stay in position relative to one another.

It was discovered that resin in a packed bed could be moved around easily in a column as a solid, unfluidized plug by a sudden jerk applied with either suetion or pressure. The movement is like that of a piston. The frictional force between the column wall and the particles belng less then that between the particles themselves, the particles eling together and slide in the colum as if lubricated by a film of liquid at the wall. The particles renain in the same position relative to one another because the movement is of auch veloeity that the resistance of 11 quid flow through the bed does not allow enough 11 quid to enter to overcame the frictional forces between the particles. Ponsibly both the fluidizing and the free settling velocities of the resin are exceeded during the movement at such a rate that the particles do not have an opportunity to separate from each other. Fluidization has been discussed by Jury. (6)

Since it is irpossible to move the resin in this manner at the same time 11quid is flowing through the bed, the solution flows are stopped momentarily to move the resin. This operation would approach true continuous differentiel countereurrent contact in the linit that the bed vere moved instantaneously in infinitesinal increments. In practice this condition is approcimated elosely by moving a relatively small fraction of the bed at a time and keeping the "off" time small in camparison to the "on" time. The disadvantages of power-driven valves and an autanatic timing system in the continuous contactor are balanced against the disadvantages of lower flexibility, closely controlled flow, and elosely graded resin needed in the "dense" falling-bed systems.

\subsection{Deta1ls of Equipment Operation}

F1gure 5.1 shows, schematically, the equipment arrangement. The rat10 of solution to resin flow desired is determined by the punpopeed and the amount of resin moved per cycle. The "down-t1me", to accamplish the resin movement, and the fraction of the bed moved per cyele are inversely proportional and are balanced to keep each at a practical minimum. The timer is arranged to $g$ ive each operation 1 ts proper sequence and duration.

The cycle occurs in the folloring sequence:

1. The pumps stop. Solution inlet and outlet valves close.

2. The plug valve between the resin columns opens.

3. The bellows flex to move the resin bed, which slides as a piston.

4. The plug valve between the columns closes and the plug valve in the reservoir column opens.

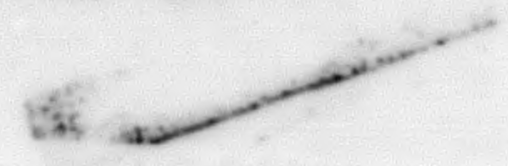


5. The bellows return to their original position, adding a "kick" to the resin settling frcm the top column to the reservolr of packed resin, which is pulled in at the bottan in step 3 .

6. The plug valve in the reservoir leg closes.

7. The pumps start. Solution inlet and exit valves open. The solution flows until the next resin movement period.

\subsection{Development of the Equipment}

In the original hand-operated equipment, shown in Figure 5.2, flow was controlled by direct measurement of volume throughfut. The resin was moved by applying a vacuum at the feed tanks. Valves vere operated manually. Beveral demonstration runs and a "contest" 5 ) with a conventional fised bed were carried out with this equipment.

The use of a power-driven bellows vas suggested to give an aceurately measured resin flow. Th1s vorked out very well on an automatic model, shown In F1gures 5.3 and 5.4. A larger contactor is under construetion which has a bellows for a 4- to 6-1n. column. For columns larger than $1 \mathrm{ft}$. In diameter, use of a bellows may be impractical and the use of a piston or a hydraulie pump is ouggested. When corrosion of or leakage from the resin movement mechanism 1s of concern, an inert 11 quid which is inmiscible with the process solutions may be used in the mechanism.

In the autcmatic contactor (F1gure 5.4) two separate bellows are pover ariven by means of a rocker arm and one air motor. The column of resin is both pushed and pulled. The same effect can be accamplished by one bellows sealed in a can, but this requires a packing gland around the shaft driving the bellows. It was found possible also to move the resin bed by a ingle bellows, which either pulis or pushes the resin bed, if bleed valves are opened at the same $t$ ime. The bleed valves are suggested to eliminate the cost of the second bellows or to eliminate the packing gland in the single canned bellows mechanism. A bellows provides an aceurate resin flow and can be adjusted by changing the stroke. The hyaraulie pump, al though more simple and ecmpect for larger columns, would require a detector to signal how much resin had been moved.

For camplete recirculation of the solid it is necessary to have at least one valve to allow pessage of the resin bed. The plug-cock type of valve is 1deal, but an air-driven pinch valve has also been used successfully. For large-column installations it is not necessary to increase the openinf size of this valve proportionately. Hovever, as the column gets larger relative to the valve opening, greater consideration must be given to streamlining. If the solutions in the sorption and serubbing sections (or serubbing and stripping) need not be separated from each other, th1s valve may be placed in the reservoir resin bed, which is irept smaller 
to reduce resin inventory. Not only the valve placement but the gecmetry of the columns will vary with each application, depending on the desired flow rates, equilibration rates, and desired product purities.

\subsection{EXAMPIBS OF RECOVERY AND CONCENIRATION}

Runs were made with the autcmatic model to demonstrate the recovery and concentration of Iron and cerium. In one experiment (Figure 6.1) ferric 1 on at $1.35 \mathrm{~g} / 11$ ter in $0.25 \mathrm{M} \mathrm{HNO}$ was fed at $10 \mathrm{mi} / \mathrm{min} / \mathrm{cm}^{2}$ to a 17-1n. bed of Nale1te BCR. The "loaded" resin vas moved fram the solution feed end of the sorption section into the solution exit end of a $28-1 \mathrm{n}$. desorption ("strip") section. The iron vas eluted from the latter section at 11 to $15 \mathrm{~g} / 11$ ter with $0.8 \mathrm{M}$ cxallc ac1d at a flow rate of about 1 $\mathrm{ml} / \mathrm{min} / \mathrm{cm}^{2}$. Only $0.2 \%$ of the 1 ron was lost in the feed vaste. This run continued for more than $100 \mathrm{hr}$ almost wholly unattended. Control vas acecaplished by adjusting the resin movement rate and the oxalic acid strip rate to maintain a dark band of ferric-form resin at the top of the sorption section and at the bottam of the desorption section. In a secand experiment (Figure 6.2) cerous 1 on at $1 \mathrm{~g} / 11$ ter in $0.25 \mathrm{M}$ HNo, was fed to a 28-1n. colymn of 50- to 100-mesh Dowex-50, 12\% cross-1Inked, at 10 to $20 \mathrm{ml} / \mathrm{min} / \mathrm{cm}^{2}$. The cerium vas ecncentrated by a factor of about $15 \mathrm{in}$ a 48-1n. strip column using $6 \mathrm{M} \mathrm{HHO}_{3}$ as eluting agent. About $0.05 \%$ of the cerium was lost in the feed waste, but the recovery of this vas limited by the background counting of the Ce14h tracer. The $15 \mathrm{~g} / 11$ ter product concentration is not considered the maximum possible because the strip-tofeed ratio vas 1 imited by the speed range of the pumps used. For recoveryconcentration problems where the desired product is present at a low concentration in a dilute (In total electrolyte) feed, it is visualized that the sorption column wil be short. and wide relative to the desorption column.

\subsection{EXAMPLES OF SEPARATIOI}

Two runs vere made to demonstrate the separation of two 1ons, both on the hand-operated contactor. In the first such experiment uranium and cesium vere separated in $0.5 \mathrm{M} \mathrm{H} \mathrm{SO}_{\mathrm{h}}$, in which the separation factor is 3. The separation section and the stripping section of the column vere each $17 \mathrm{in}$. Iong. The resin was Dowex-50, 12\% eross-11nked and 60 to 100 mesh. The relative rates of movement of cesium and uranium down the colum with $0.5 \mathrm{M} \mathrm{H} \mathrm{SO}_{\mathrm{h}}$ had been previously determined on a conventional fixed bed. These retios of solution to resin flow vere incorporated in the operation of the continuous contactor such that uranium continuously moved down the bed and cesium continuously upvard. To econcmized on eluting chemicals and build up the cesium concentration, a portion of the cesium product solution was used as the serub feed. A continuous product of uranium eolution was obtained at a concentration of about $0.4 \mathrm{~g} / 11$ ter; it contained only about 10 to $20 \mathrm{c} / \mathrm{min}$ of $\mathrm{Cs} 135,137$ tracer per milliliter. The cesium product contafned about $0.005 \mathrm{~g}$ of uranium per 11 ter and had an activity of about $5 \times 10^{4} \mathrm{c} / \mathrm{min} / \mathrm{ml}$. ' $\mathrm{mis}$ is one of the runs ineluded in the comparison with the conventional fixed bed to demonstrate the increased 
efficiency with countereurrent flow. (5)

Figure 7.2 shows the results of a separation of barium and strontium with a separation factor of 2 . The feed contained $10 \mathrm{~g} / 11$ ter each of barlum and strontium with $\mathrm{Ba} 140$ and $5 \mathrm{r} 89,90$ tracer. The separation vas made in $2 \mathrm{M} \mathrm{HmO}_{3}$ on Dowex 50, $12 \%$ eross-11nked and 60 to $100 \mathrm{mesh}$. The run vas controlled by measuring the relative resin and solution flow rates and flase testing the barium and strontium product streans. As shown in the figure, ouling to an initial error in operation, the run got out of eontrol but finally leveled off at about $10 \%$ of the barium in the strontium product and 0.34 of the strontium in the barium. product.

\subsection{BIBLIOGRAPHY}

(1) "Plasties that Sort Atcms," Portune, p. 107, July, 1951.

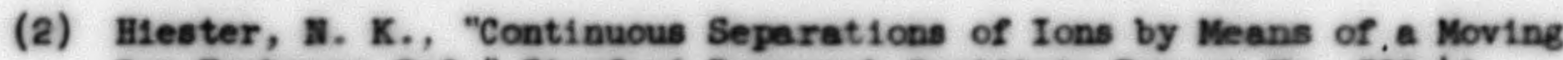
Ion-Bxchange Bed," Stanford Researeh Institute Report No. coo-41 (March 30, 1951).

(3) Selke, w. A. and liarding B11ss, "Continuous Countercurrent Ion-Bxchange," Chem. Bng. Progress, 47, 529 (1951)

(4) Devey, D. R. and J. A. Marinsky, "Ionice Rectification Column," paper delivered at Gordon Research Conference in 1951 (in press).

(5) Roberts, J. T., "An Bxperimental Comperison of the H1ggins Continuous Ion Bxchanger with a Conventional Fixed Bed Column," ORan. CF-52-6-107 (June 18, 1952).

(6) Jury, S. H., "Continuous Ion Exehange Column Investigat1ons," ORun. CF-50-9-80 (August 31, 1950).

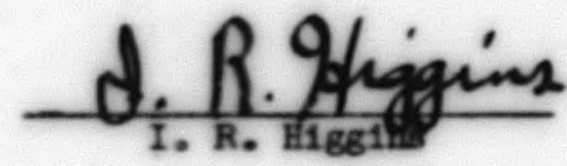




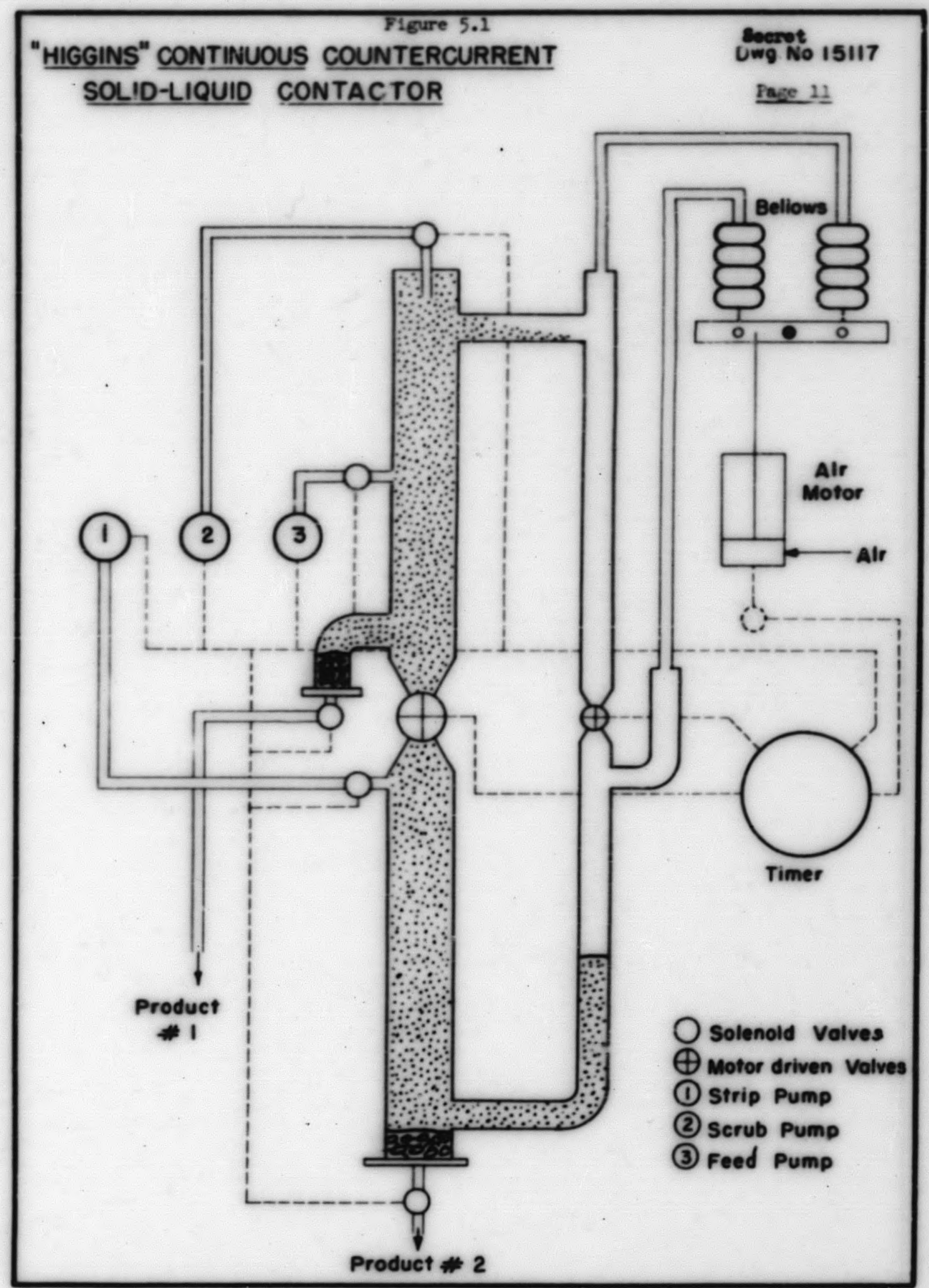


$-12-$

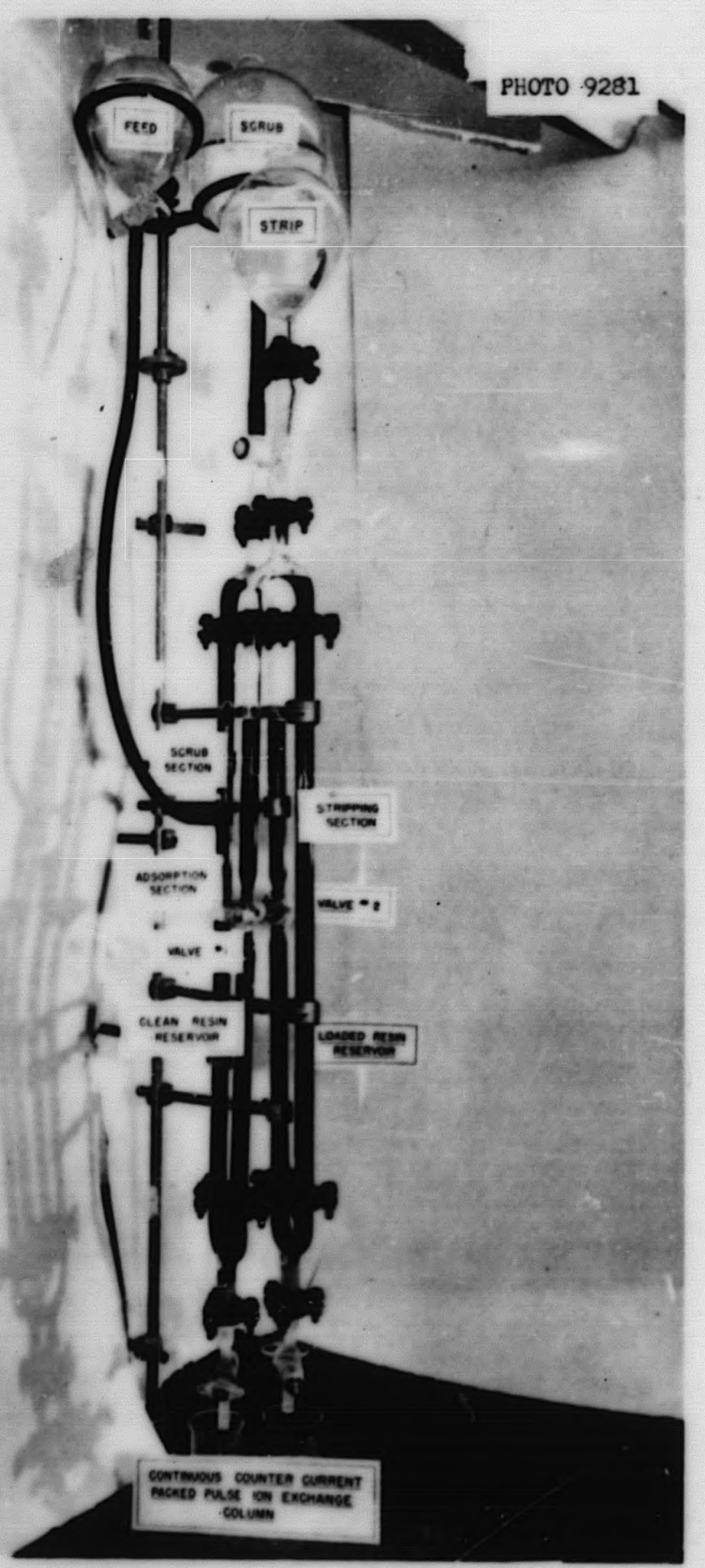

Figure 5.2 Original Laboratory-scale Hand-operated Contactor 


\section{$-13-$}

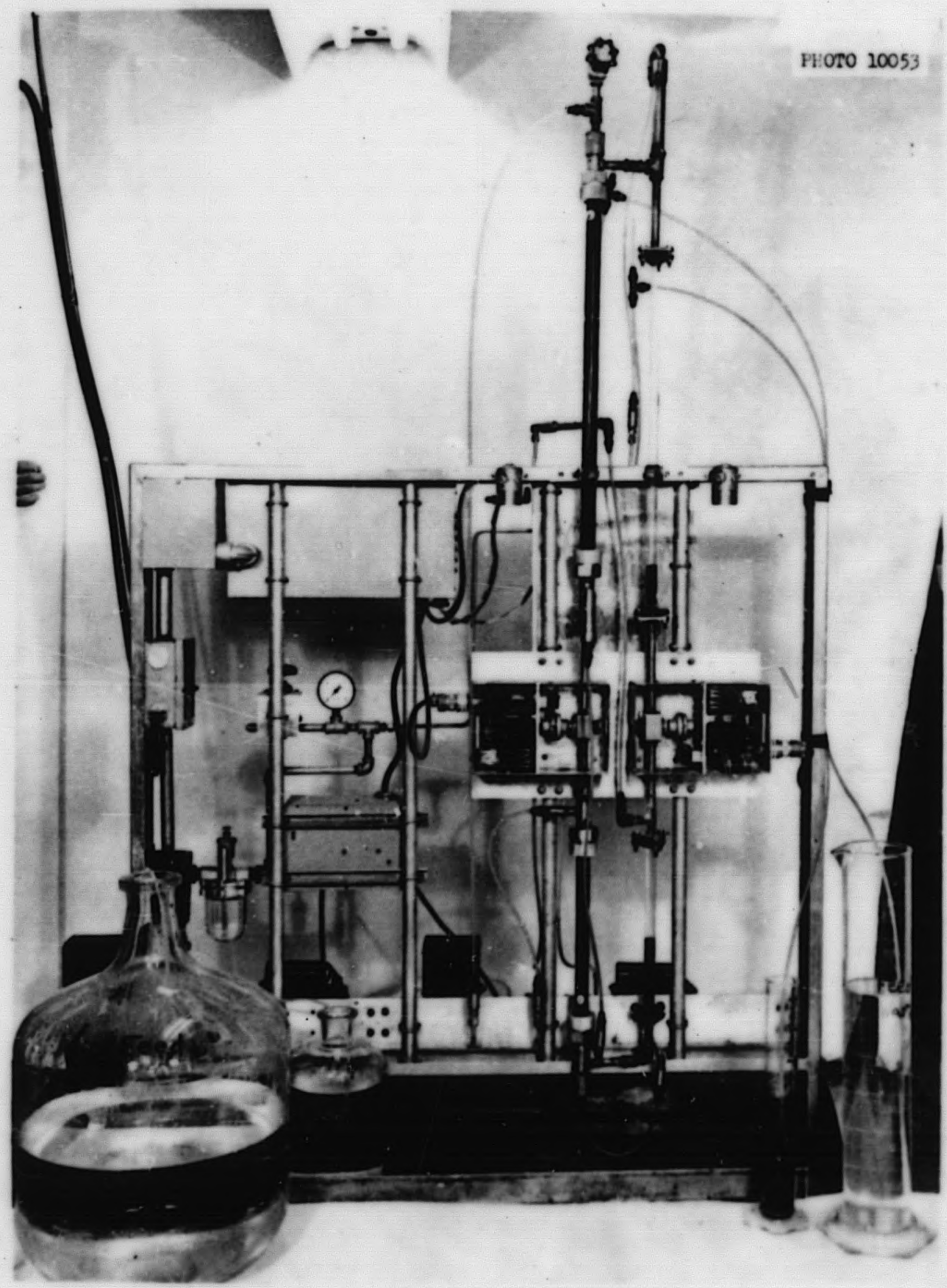

F1gure 5.3 Laboratory-scale Automat1c

Contactor, Showing Column Arrangement and Motor-driven Resin Plug-valves 


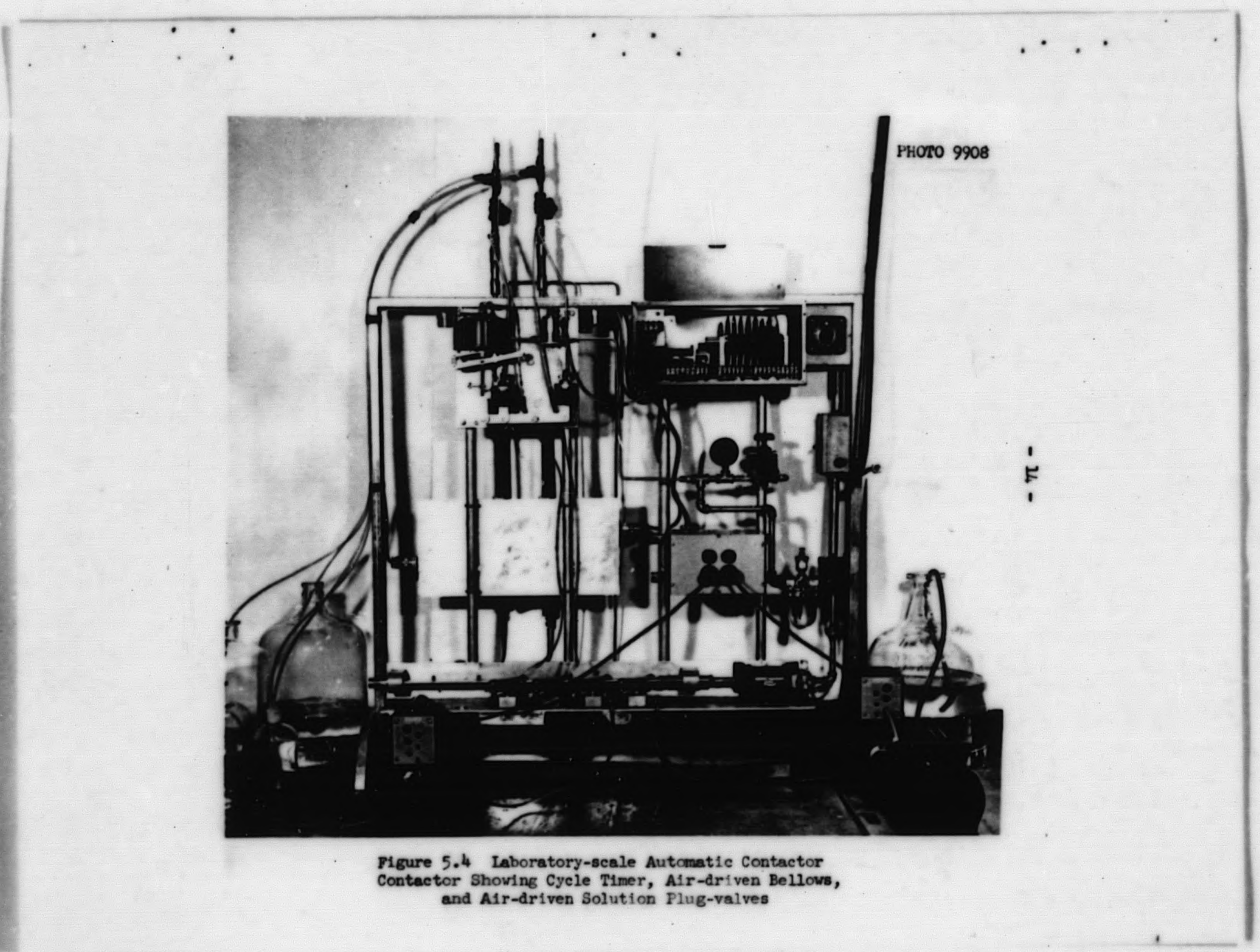




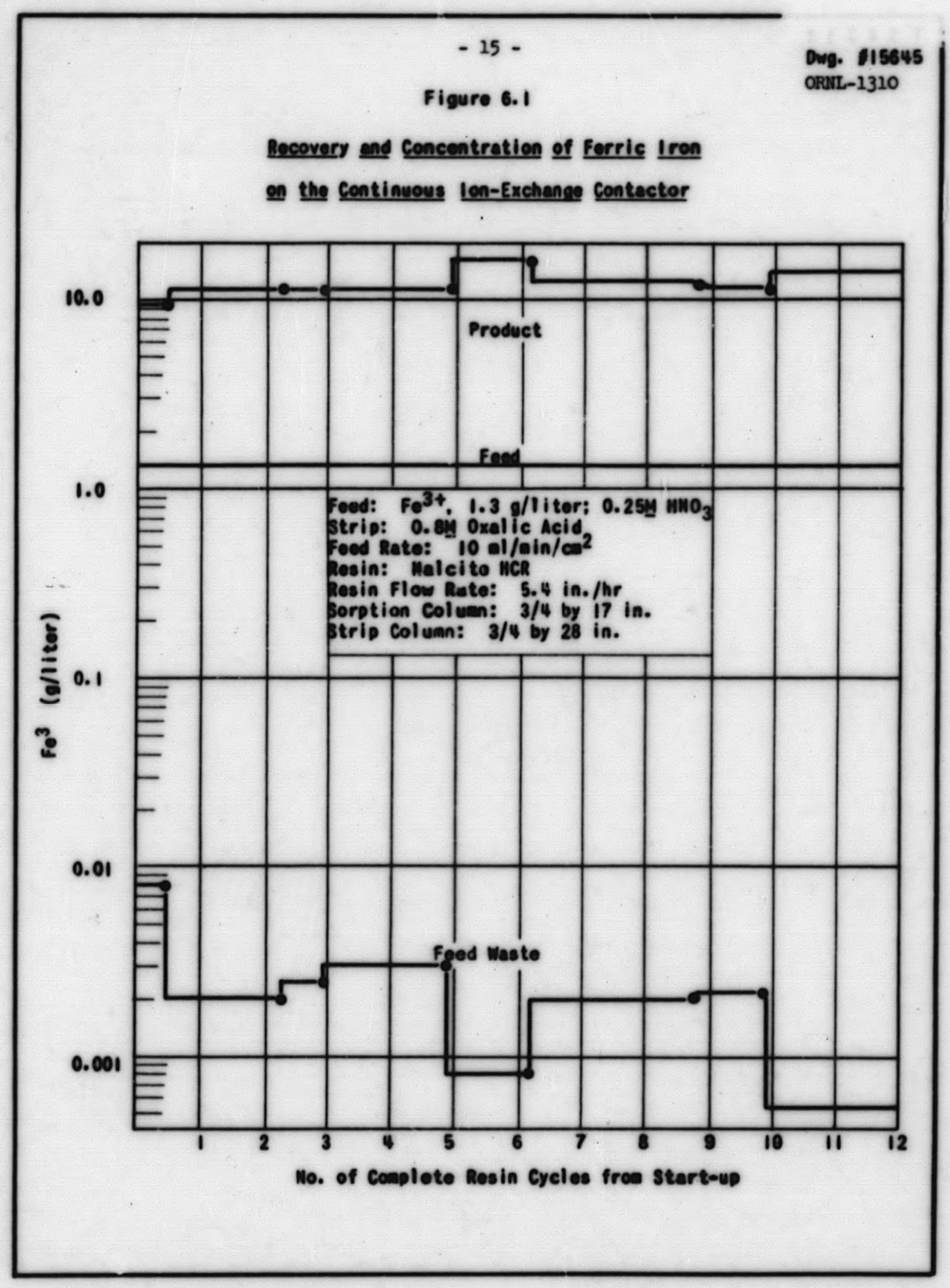




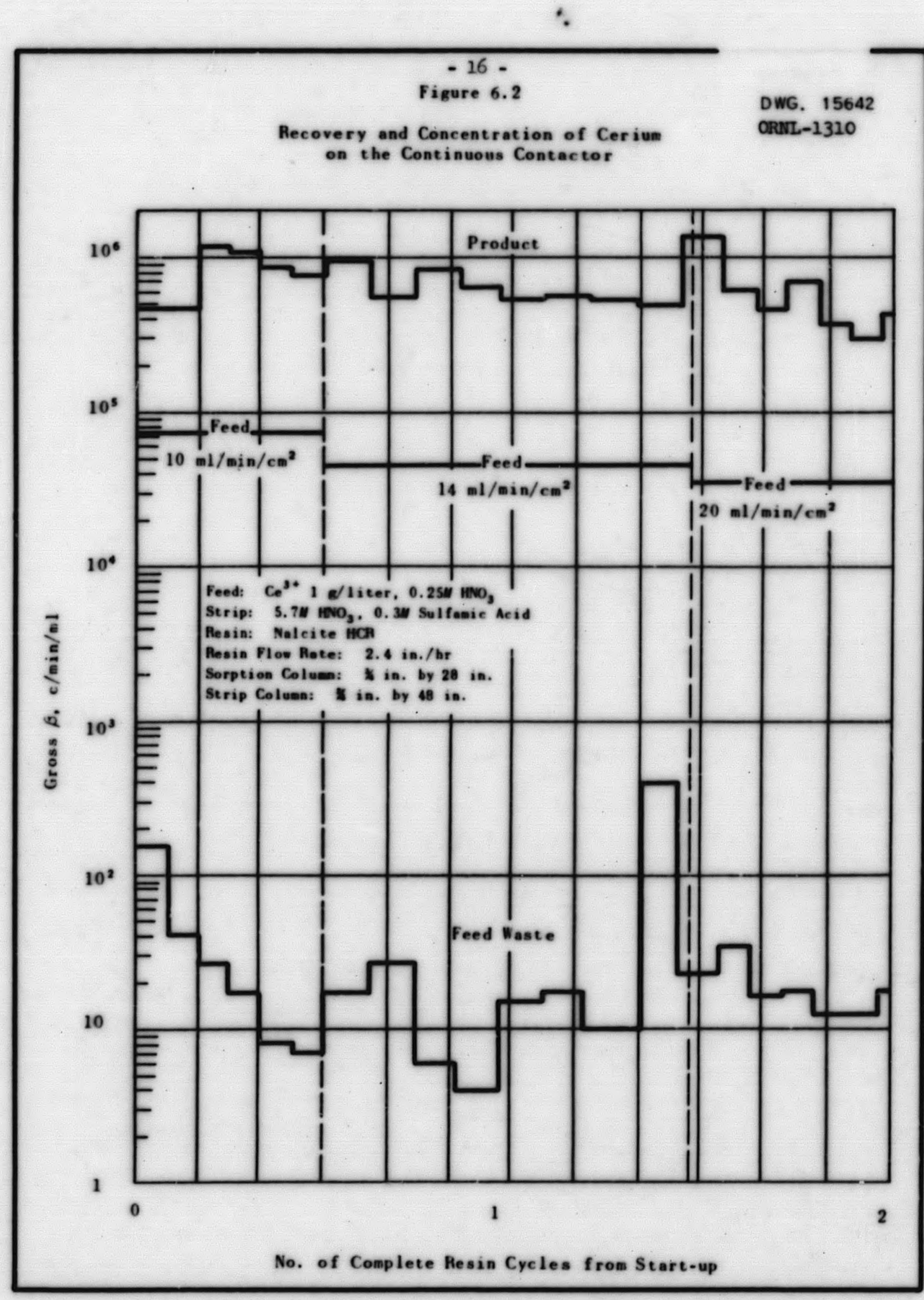




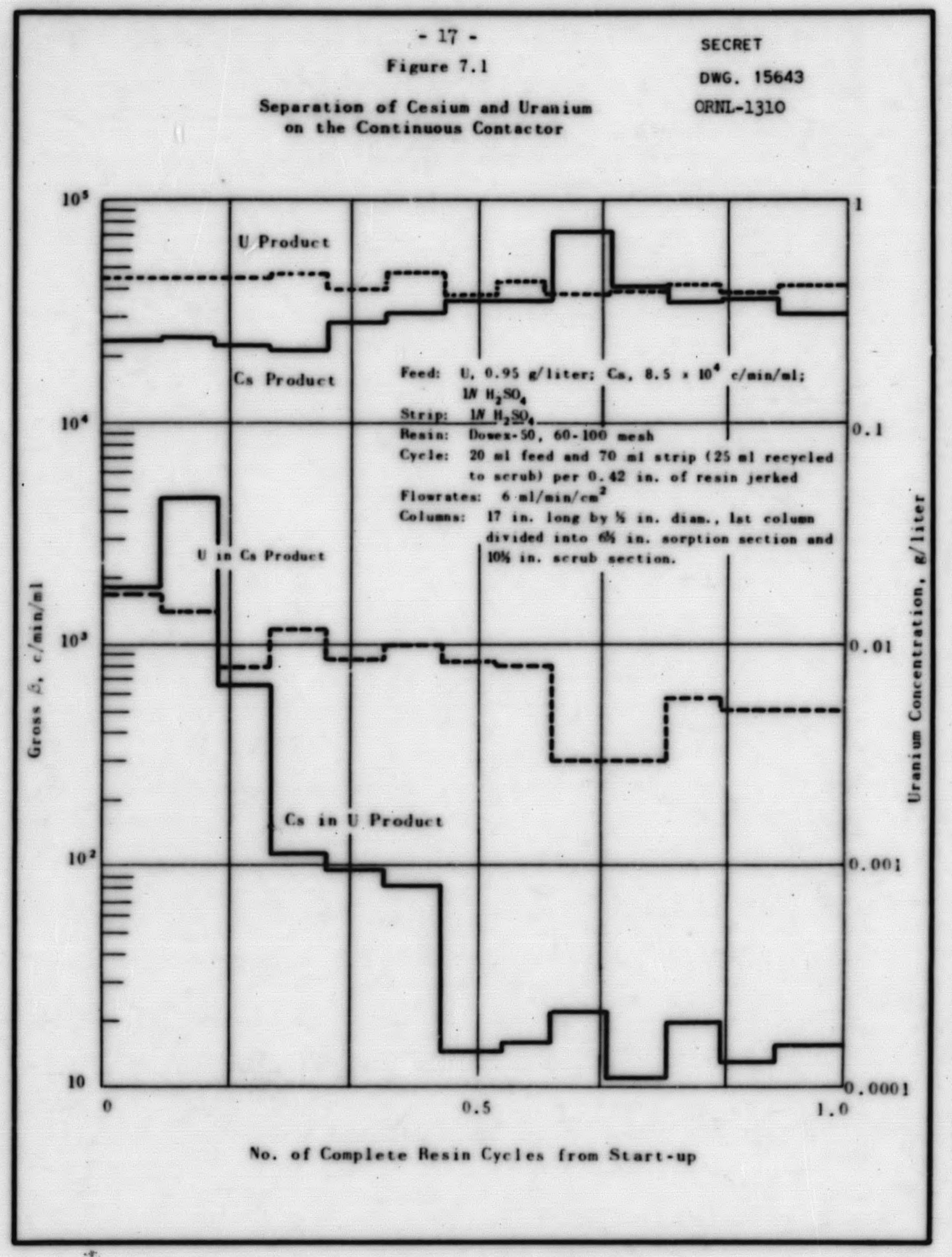

$+$ 


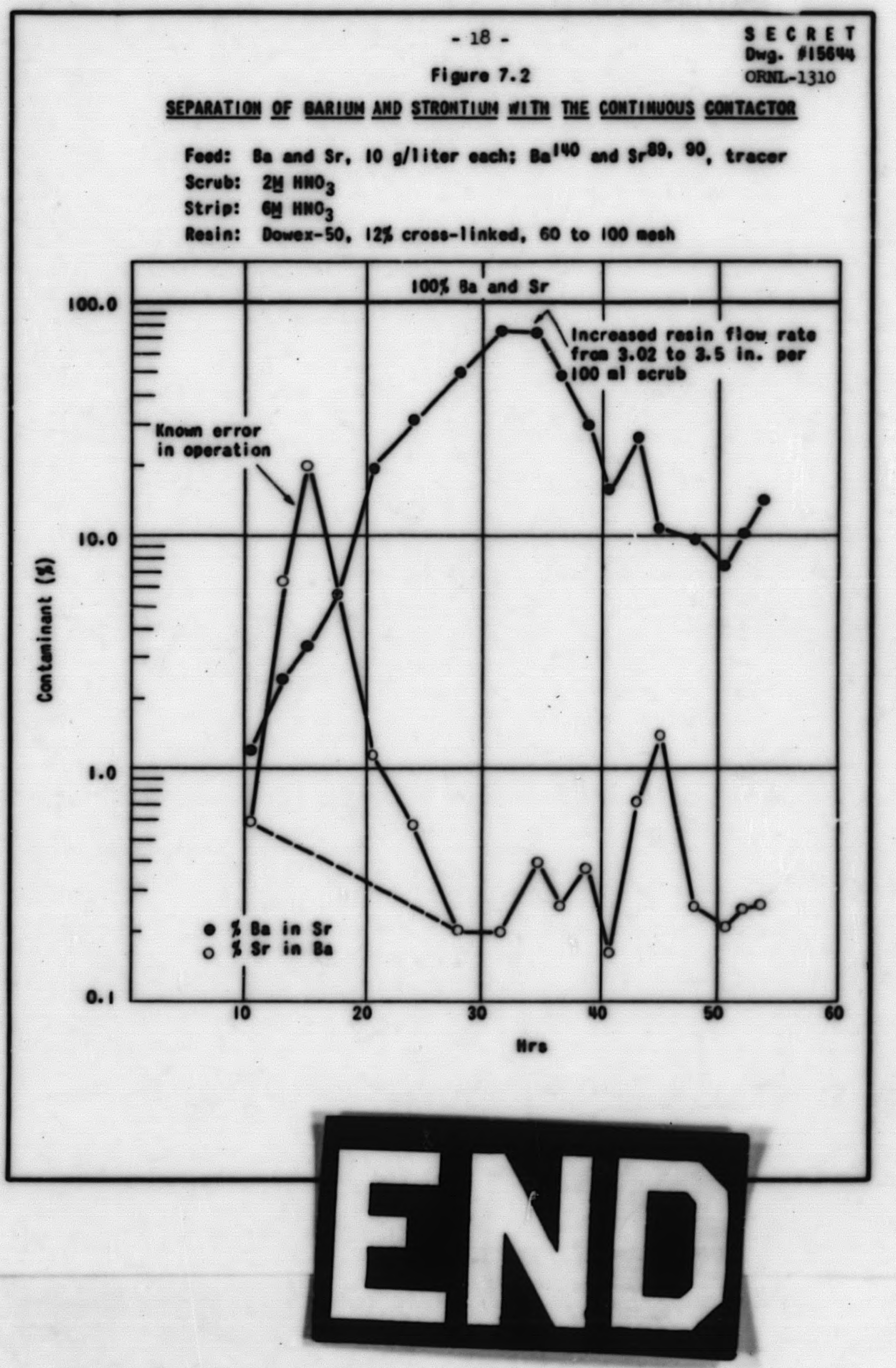

